\title{
Los infortunios de Waldemar Haffkine
}

\author{
WALTER LEDERMANN D.
}

\section{The misfortune of Waldemar Haffkine}

En la investigación científica se presentan encrucijadas en donde es preciso elegir una senda u otra, ambas igualmente atractivas. Un ángulo muy agudo puede separar la ruta verdadera de la falsa, y quien toma el desvío y va al fracaso, bien pudo, por simple azar, tomar el camino real y llegar al éxito y a la gloria. Investigadores tan talentosos y esforzados como los que figuran en las actuales listas de la fama, yacen hoy en el olvido, después de haber conocido un éxito momentáneo.

Waldemar Mordecai Haffkine (1860-1930), "un bacteriólogo ruso que trabajó en India"1, es un buen ejemplo de esta situación, luego de haber desarrollado durante su carrera una serie de vacunas promisorias y de procedimientos exitosos:

- la vacuna de Haffkine, un cultivo de caldo, envejecido y estéril, de Yersinia pestis;

- una vacuna anticólera con una cepa viva y atenuada de Vibrio cholerae, conocida también como la vacuna de Ferrán-Haffkine;

- un suero antipestoso;

- la haffkinina, una preparación de atebrina;

- la haffkinización, un singular procedimiento de inmunización con su suero antipestoso ${ }^{1}$.

De todo ello sólo resta el recuerdo de su vacuna contra la peste bubónica, la primera usada en seres humanos y cuyo principio respeta la actualmente en uso, que dista de ser una maravilla. En la encrucijada, Haffkine tomó el camino trillado de su época, trabajar con bacterias enteras, muertas o de virulencia atenuada: fracasó así frente al cólera, que es una enfermedad producida por toxina, y fracasó parcialmente ante la peste, porque los procedimientos de la época no le permitían seleccionar los antígenos correctos.

En un feliz instante de su vida, Waldemar Mordecai gozó de mucho prestigio y llegó a dirigir un laboratorio de vacunas en Bombay. Por desgracia y no por culpa personal, sus dos vacunas se vieron envueltas en accidentes fatales, provocando al infortunado investigador años de amargos sinsabores. El primero ocurrió en noviembre de 1902, durante una gran campaña de vacunación contra la peste bubónica en el Punjab, donde 19 personas que habían sido inmunizadas en el pueblo de Mulkowal fallecieron de tétanos. La causa de este desgraciado accidente, conocido como el desastre de Mulkowal ${ }^{2}$, permaneció en discusión durante cuatro años y, aunque finalmente la inocencia de Haffkine pareció probarse, fueron para éste cuatro siglos de angustia.

La campaña de vacunación iniciada por el gobier- no del Punjab proyectaba inmunizar algo más de medio millón de habitantes con dos variantes de la vacuna de Haffkine. Sus metas, bastante mesuradas, buscaban reducir la mortalidad a un cuarto de lo habitual y la letalidad a un doceavo, lo cual significaba, en líneas generales, salvar unas diez mil vidas. Por desgracia, entre el 5 y el 6 de noviembre, 19 personas vacunadas el 30 de octubre en Mulkwal con el lote $53 \mathrm{~N}$ desarrollaron claros síntomas de tétanos y fallecieron entre el 6 y el 9 de noviembre. Inmediatamente se constituyó una comisión investigadora, cuyos resultados vinieron a publicarse recién el 1 de diciembre de 1906 en un suplemento de la Gazzete of India, siendo mayormente el fruto de estudios realizados por el Instituto Lister de Inglaterra.

Pudo establecerse que aquel día se habían utilizado 5 botellas que provenían del mismo frasco de cultivo $53 \mathrm{~N}$. Con una se vacunaron sólo las 19 personas fallecidas; las otras cuatro se utilizaron en otro lugar y no causaron tétanos. Las 19 víctimas se inmunizaron con la misma jeringa, que se lavó con una solución de ácido carbólico antes de volver a llenarla con el contenido de otro frasco, que tampoco causó daño. La discusión se centró entonces en dos posibilidades: a) que la botella se había contaminado en origen, al ser llenada 41 días ante en el laboratorio de Haffkine; b) que la jeringa se hubiese contaminado con tierra tetánica el mismo día 30 de noviembre.

Los experimentos realizados para probar una $\mathrm{u}$ otra de estas hipótesis fueron desde lo rigurosamente científico a lo puramente pintoresco: desde la determinación de la dosis infectante y letal de la cepa de Clostridium tetani involucrada, hasta la prueba de olfato, que rindió el distinguido Dr. Elliot para reconocer el olor del cultivo contaminado. Considerando el escaso desarrollo de bacilo tetánico que se encontró en el remanente de la botella implicada, parecía improbable que fuese el fruto de una incubación de 41 días; además, su olor no había impresionado al vacunador al abrirla el día 30 de octubre. Así, cabía suponer que este mismo operador había contaminado la jeringa. En apoyo de esta tesis estaba la forma de presentación de la enfermedad, que correspondía a la corriente en el Punjab, esto es, al bajo inóculo en un instrumento cortopunzante contaminado, y no a la inyección de rico cultivo de 41 días en anaerobiosis, que habría llevado a una muerte más rápida.

Quedaba, sin embargo, una pregunta para exonerar de culpa a la jeringa: ¿cómo se explicaba que este 
instrumento, contaminado con bacilo tetánico al punto de matar a 19 personas al hilo, perdiera todos su peligro luego de una simple lavadita en una solución carbólica? Al respecto, el teniente coronel Semple realizó un interesante experimento reproduciendo todas las condiciones del accidente: después de lavar la jeringa como se hizo en Mulkowal, inoculó una serie de animales, logrando demostrar que todo dependía de la cantidad de inóculo, pues si trabajaba con un cultivo puro, como hubiera sido una botella infectada en origen, morían 17 de 19 animales, en tanto que con un inóculo pobre, propio de una contaminación momentánea, el lavado carbólico bastaba para preservar la vida de los animales.

Waldemar Haffkine envió tardíamente sus comentarios al Subsecretario de Estado de India, todos de índole científica y no personal. Habría tenido derecho a reclamar, pues si bien el informe final le había sido favorable, la lentitud del procedimiento para emitir un tardío dictamen le había sido francamente perjudicial, permaneciendo durante cuatro años en la picota científica. Comentando el caso, Lancet echaba de menos una declaración pública del Gobierno de India aclarando la inocencia de este "distinguido servidor"2.

La "absolución" de Haffkine apareció publicada el $1^{\circ}$ de diciembre de 1906. Sin duda, en noviembre del mismo año, el sabio investigador ya estaba al tanto de ella y veía ante sí un futuro tranquilizador. Podemos imaginar su abatimiento al enterarse por la prensa que el día 16 el Dr. Richard Strong había inoculado en la prisión de Bilibid, en Manila, a 24 "voluntarios" con una vacuna viva anticólera preparada según el procedimiento de Haffkine, a raíz de lo cual habían fallecido 13 de ellos. Lo verdaderamente increíble de este nuevo desastre ${ }^{3}$ es que los prisioneros no fallecieron de cólera, sino de... ipeste bubónica! ¿Cómo pudo contaminarse de tal manera una vacuna? Es un misterio digno de una película de Hitchcock.

Richard Pearson Strong (1872-1948), un brillante investigador en el campo de la medicina tropical, graduado en Yale y en John Hopkins, era jefe del Laboratorio Biológico de la Oficina Filipina de Ciencias, donde probaba en voluntarios humanos vacunas contra el cólera y la peste. La forma artesanal en que preparaba sus vacunas, como se comprobó en las investigaciones posteriores, lo llevó al espantoso error de trabajar en ambas al mismo tiempo.

Todo este episodio de Bilibid es oscurísimo. El viernes 16 de noviembre de 1906 el Dr. Strong acababa de preparar su vacuna de Ferran (según método de Ferran-Haffkine) cuando se presentó en su laboratorio "un doctor de Chicago", del cual nunca se supo el nombre ni la nacionalidad, aunque se le supuso holandés: nadie lo buscó para declarar durante las investigaciones. Strong, quien venía de preparar su vacuna con $V$. cholerae, le mostró unos tubos con Yersinia pestis a su visitante, "quien tomó uno en sus manos". Luego este fantasmagórico "doctor de Chicago" le dijo a Strong que necesitaba algunas referencias, las cuales estarán sin duda en la biblioteca de la institución y éste, servicial y diligente, salió a buscarlas. Cuando su visita se hubo ido, Strong tomó su gradilla con tubos de cultivo colérico y se fue a la prisión de Bilibid, donde inoculó a 24 reos. Estos comenzaron a enfermar y a morir rápidamente, demostrando las autopsias que morían de peste y no de cólera. Una sospecha atroz cruzó por la mente de Strong y corrió a su laboratorio: en la estufa faltaba un tubo de cultivo pestoso. Strong hizo como todo bacteriólogo: buscó en el tarro de tubos eliminados y allí, todo borroso por la solución desinfectante, encontró en uno el rótulo de Yersinia pestis. Sin embargo, parece evidente $-\mathrm{y}$ no cabe otra explicación- que el visitante puso, por error, el maldito tubo en la gradilla de cólera. Ahora, a la distancia, uno se pregunta si este visitante existió, o si fue sólo una infantil argucia de Strong para ocultar su propio descuido.

El Gobernador General de Filipinas designó un Comité Investigador, el cual encontró a Strong culpable de negligencia, derivando el caso a la Fiscalía. Ésta consideró que el investigador era inocente y en consecuencia el Gobernador lo exoneró de toda culpa. En Estados Unidos, si bien no fue sometido a un juicio formal, Strong fue objeto de duros comentarios, que hicieron al Senado solicitar al Secretario de Guerra un completo informe de los hechos, los que también fueron puestos en conocimiento del Presidente T. Roosvelt. Los experimentos con prisioneros fueron prohibidos.

Lo sorprendente del caso es que Strong sobrevivió, como científico, a esta catástrofe y continuó trabajando en el mismo laboratorio. En 1911 lo encontramos investigando la peste bubónica en Manchuria, con el apoyo de la Cruz Roja y del Departamento de Guerra de EE.UU., al cual representa en la conferencia internacional sobre el tema en Mukden. Ahí se encuentra con el sobrino de Waldemar Haffkine, el doctor Paul B. Haffkine, entonces director del Hospital Ruso para la peste en Harbin... Pero, más que sorprendente, es aberrante cómo Strong reincide en sus prácticas: en 1912 conduce, con autorización oficial, un experimento en Bilibid en prisioneros condenados a muerte, para determinar si una determinada dieta de arroz les producía beri-beri. En premio, los 29 "voluntarios" recibirían todos los cigarros y puros que quisieran, sin importar la marca....

Waldemar Haffkine no fue del todo rehabilitado con la publicación del fallo en la Gazette of India, al punto que el célebre investigador de la malaria Ronald Ross hubo de reunir las firmas de varios prominentes científicos de la época, en una carta de desagravio publicada en el London Times del 29 de julio de 1907. Pero su desgracia no terminó allí. El Dr. Freer, superior directo de Strong, publicó el episodio de Bilibid en el JAMA ${ }^{4}$ el mismo año 1907, ocasionando que el Home Office, con fecha 6 de julio de 1908, es decir, cinco años y medio después del infortunado accidente de Mulkowal, instruyera al doctor Haffkine en el sentido de suspender cualquiera inoculación anticólera en India. Haffkine replicó con una defensa de 14 páginas, explicando sus procedi- 
mientos, y el Home Office, en representación del gobierno británico, finalmente lo autorizó a continuar el 12 de septiembre, expresando, eso sí, que toda inoculación sería responsabilidad personal del investigador.

¿Quisimos saber que fue de Haffkine posteriormente y recurrimos a nuestra voluminosa enciclopedia. En la letra hache, Haffkine debiera figurar entre el poeta persa Hafiz y nuestro homónimo Walter Hagen, un golfista profesional que, en un arranque de modestia, escribió su propia biografía (The Walter Hagen story) ${ }^{5}$. Debiera figurar, pero no aparece, lo cual prueba que el hombre, aunque sostenga lo contrario, valora siempre más el circo que la ciencia.

\section{Bibliografía}

1.- Dorland's Illustrated Medical Dictionary. 22th ed. WB Saunders, Philadelphia 1951; pp. 642 y 1660.

2.- The Mulkowal disaster. Lancet 1907; 1: 299-302.

3.- Chernin E. Richard Pearson Strong and the iatrogenic plague disaster in Bilibid prison, Manila, 1906. Rev Infec Dis 1989; 11 (6): 996-1004.

4.- Freer P. Accidental inoculation with the virus of plague. JAMA 1907; 48: 1264-5.

5.- Collier's Encyclopedia. Crowell Collier \& McMIllan, USA 1967; 11: 571 